УДК 622.235

V. Kravets, Dr. Eng. Sc., Prof., A. Shukurov, Ph.D. student, Igor Sikorsky Kyiv Polytechnic Institute

\title{
MODELING AND PRACTICAL APPLIKCATION OF A POWER FIELD AT CONIC CHARGE EXPLOSION
}

В.Г. Кравець, д.т.н., проф.

А.М. Шукюров, аспірант, КПІ ім. Ігоря Сікорського

\section{МОДЕЛЮВАННЯ І ПРАКТИЧНЕ ВИКОРИСТАННЯ СИЛОВОГО ПОЛЯ ПІД ЧАС ВИБУХУ КОНІЧНОГО ЗАРЯДУ}

An analysis over of character of the isodenses of conical charge explosive products, got by mathematical design, is brought. The features of distribution of the power field are certain depending on direction of initiation of the truncated conical charge. The complex character of intermediate initiator using in a downhole charge as the truncated cone at his location in the ground part of hole is discussed. It is established that the shape of the field of isolines of the density of PD is due primarily to the form of the charge, regardless of the place of its initiation; the prevailing field development occurs relative to the $Z$ axis, that is, along the $X$ axis of the conical charge by the action of its narrow part. This is due to the spread of the products of detonation normal to the sloping surface of the cone. If you associate the total area of the PD density field with the total explosive energy, it is possible to redistribute the flow of energy due primarily to the orientation of the bases and sides of the truncated cone charge, and then to its initiation location. Control of the dynamics and direction of development of the force field is possible by choosing the location of application of the initiating pulse, namely, the location of the initiator on the opposite charge basis for the development of the process in the desired direction of concentrating the energy of the explosion. Due to the specific "pear-shaped" form of the radiated energy field, the explosion of the inverted conical fighter at the stage of initiation of the main (downhole) charge directs the vector of the initial section of the stress wave front towards the upper free surface, ie towards the surface sideways. This area is not subject to the direct action of a system of compressive radial and tensile tangential loads from a charge explosion in a well. changing the direction of development of the force field toward the upper layers of the rock should contribute to better grinding of this part of the array. This method can be implemented using the mechanism of interaction of rock masses, moving towards and additionally destroyed similar to the conditions of short-delay blasting in a schematic diagram, ie, the mechanism of interaction at the level of a slower process - the collision (collision) of the mass directed to the upper side. Simultaneous lower initiation of prolonged charges in adjacent rows gives rise to the front edges inclined to the free surface of the ledge (Fig.). In fact, in this case, the scheme of a wedge or trapezoidal cut is implemented, but oriented instead of the lateral free surface towards the roof of the ledge, which because of its large area is the main source of oversized fractions. consists in the simultaneous simultaneous detonation of three adjacent series of downhole charges treated as one group, followed by the short-term detonation of the adjacent three-row group and the like. The implementation of such a scheme allows to take advantage of its advantages by combining mechanisms of movement of masses in 
the vertical direction and traditional movement with the coincidence of areas of the array in the horizontal direction. The advantages of using a mixed circuit switching scheme have been proven by industrial testing of the method.

Keywords: the concentrated charge, mathematical design, isolines of density, stream of energy, mode of initiation, field vector, over drilling

Introduction Concentrated charges in mining technologies are mainly used either as an intermediate initiator (booster) in the main borehole charge, or independently as overhead or cumulative cartridges in secondary blasting operations. Moreover, their detonation characteristics and the nature of the spatial distribution of the energy emitted by such a charge are minimally taken into account or ignored.

In most theoretical studies regarding the controlled mechanical effect of a concentrated charge, it is believed that its initiator occurs either instantly or from its center, which greatly simplifies the solution. In this case, the central symmetry of the stress and strain field in surrounding isotropic medium, repeats concentrically the symmetry of the charge in its development, especially in the near explosion zone, at the contact with the medium.

Under real conditions of detonation of a charge with any design through the sequential time movement of the detonation front from the initiator to the opposite end of the charge with the next exit of the detonation wave and, accordingly, the explosion products to the charge limit with the medium, the nature of the development of the mentioned fields is much more complicated.

Objective. The aim of the work is a model study of the detonation schedule features, the shape and nature of the emitted energy field, in the explosion of a concentrated conicalshaped charge, which to a certain extent corresponds to the shape of the active mass of the cylinder charge in its end part.

Simulation results. The study of extremely fast-moving phenomena during the detonation schedule of the explosive charge at the stage of formation of the detonation front in the charge and its subsequent transformation into a shock wave beyond the charge boundary, that is, in a destructible medium, which is possible through experimental studies that require the use of modern measuring equipment. However, through considerable expenses for such experiments, modern science gives an advantage to computer modeling of physical processes, leaving behind a limited number of experiments only the possibility of establishing the reliability of simulation results. In development of the concept of wave phenomena in detonation products (PD) when a conical charge is detonated using a two-dimensional hydrocode [1], computer simulation of the decomposition of a truncated conical charge is performed. The solution to the problem of the propagation of the detonation process is carried out in an axisymmetric formulation using equations in Euler cylindrical coordinates. The results of computer simulation are presented in the form of isolines of the density of the products of a charge explosion in the form of a truncated cone upon initiation from a narrow (Fig. 1, a) and wide (Fig. 1, d) bases. 


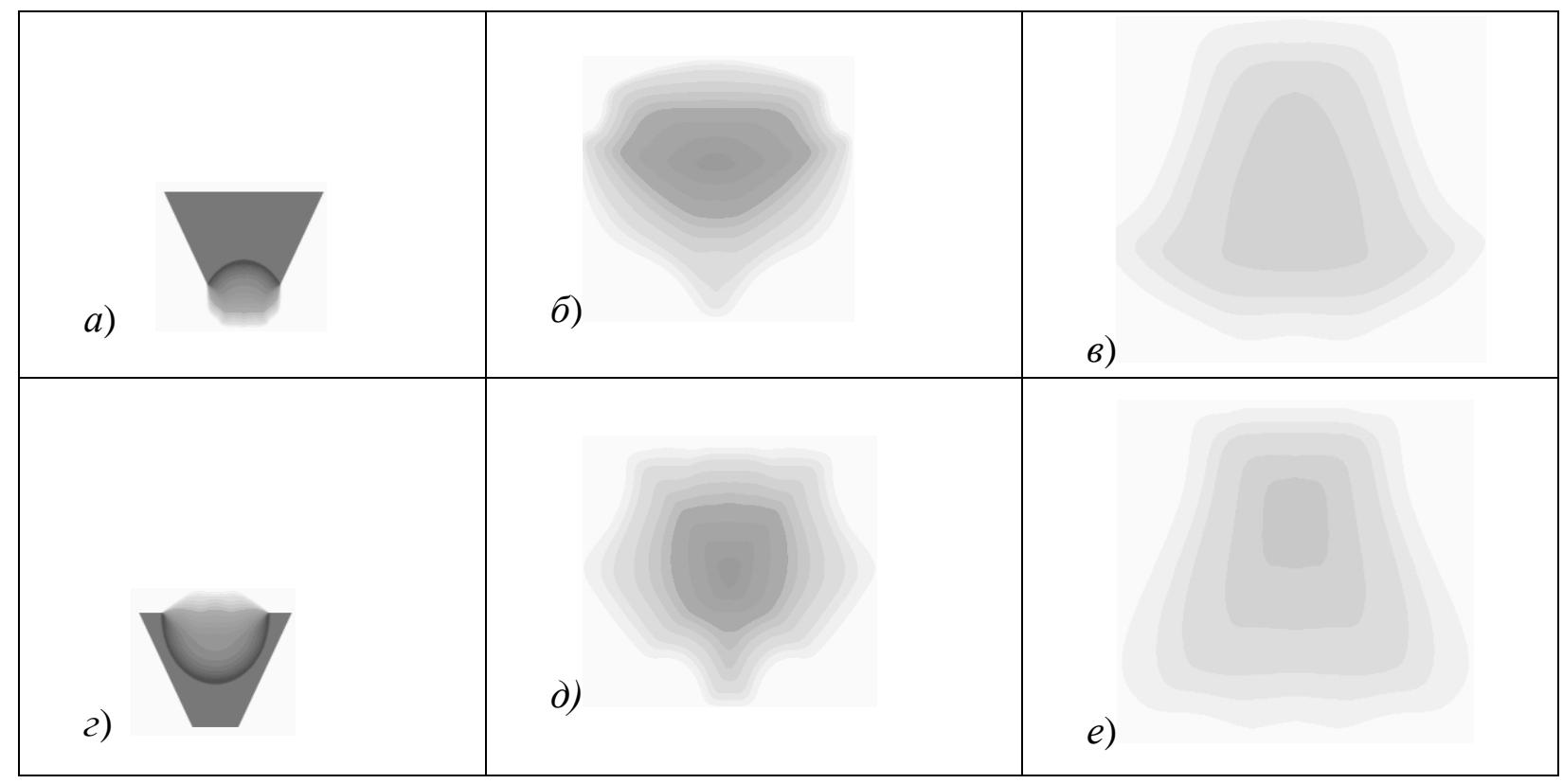

Fig. 1 Frames of the density field of conical charge detonation products - snitial (a, d), intermediate (b, e) and final (c, f): a-c - initiator from below, g-e - initiator from above

A qualitative analysis of the structure of the given fields (isolines) indicates the following:

- the shape of the isolines of the PD density is determined primarily by the shape of the charge, regardless of where it was initiated; the predominant field development occurs symmetrically along the $\mathrm{Z}$ axis and to the side of it (Fig. 1, c, f) and is caused by the expansion of detonation products along the normal to the inclined lateral surfaces of the cone;

- if the total area of the density field of the AP is associated with the total energy of the explosion, it is possible to redistribute the energy flux due primarily to the orientation of the bases and sides of the truncated conical charge, and then to the place of its initiation;

- if necessary, the direction of the energy flow and, accordingly, the deeper mechanical effect of the explosion in the axial direction (concentration along the $\mathrm{Z}$ axis), the charge should be oriented towards the obstacle with a narrow base with the initiator located on it;

- if it is necessary to obtain an effect expanded in the plane, the cone charge has to be initiated from a wide base;

- the conditions of initiation determine the predominant direction of development of the energy field, namely, along the normal to the base in the direction opposite to the place of initiation.

In support of this observation, we note that the greatest distance between adjacent contours is observed in the direction of the development of the detonation process.

The above means that the direction of the direction of the development of the force field in time by choosing the place of application of the initiating pulse is possible by the location of the initiator from the opposite base of the charge relative to the desired direction of concentration of the explosion energy.

A characteristic element of the process is the phenomenon of the formation of a force field along the axis of the conical charge. In the direction of propagation of the detonation process in time in the force field in the process of its development, a pre-emptive impulse arises along the cone axis (Fig. 1, b, e). Subsequently, the field along the axis ceases to develop and continues to develop in width. In fact, this process looks like a field wedging into a destructible medium from the narrow base of the cone.

In general, a frame-by-frame analysis of the development of the force field shows that its configuration primarily depends on the shape of the charge itself, having a central "burst" 
along the cone axis characteristic of this charge form, different from the shape of the field during the explosion of a cylindrical charge. The field geometry is practically independent of the conditions of initiation, however, the place of initiation is the starting point for the development of the field in charge and then, respectively, in the medium. Moreover, the intensity of the development of the energy field from the explosion of the conical charge can be significantly enhanced if its initiation occurs from a wide base in the direction of the narrow base of the truncated cone.

Applied aspects of theoretical studies results. The features of the effects that are observed in this case can be used in technologies where the local mechanical effect of the explosion plays a dominant role. An example is its use as an intermediate detonator of a borehole charge. Located in the lower part of the charge, such an action movie, when oriented with its wide base up, that is, in the form of an inverse cone, can solve several problems simultaneously.

As an intermediate detonator, such a conical charge provides an optimal mode of initiation of a borehole charge due to the maximum contact of the end face of the fighter with its wide base and the initiated charge. Ideally, the top wide base of an action movie with a charge over the area should be equal to the cross section of the charge.

Due to the specific "pear-shaped" shape of the emitted energy field, the explosion of the reverse conical action at the stage of initiation of the main (borehole) charge directs the vector of the initial section of the stress wave front in the rock mass both towards the neighboring group of charges and towards the upper free surface, that is, towards surface layers located at the packing level. Since these layers are not directly affected by the system of compressive radial and tensile tangential stresses from a charge explosion in the well, a change in the direction of development of the force field towards the upper layers of the array should contribute to better grinding of this part of the array.

The greatest effect of such a reorientation of the force field can be achieved by lower initiation of adjacent borehole charges, but only if they are almost simultaneously undermined - either charges in one group, or parallel initiation of neighboring groups of charges. Only in this case, the total force field vector will be directed normal to the free surface of the block. Technically, it is rather difficult to provide such conditions because of the high propagation speed of stress waves, therefore it is more realistic to rely on the known mechanism of interaction of rock masses, that is, on the oncoming contact of the masses. Their movement is generally directed towards the free surface. In fact, in this case, a wedge or trapezoidal cut scheme is implemented, but oriented instead of the lateral free surface towards the roof of the ledge, which is the source of most of the oversized pieces.

The specific shape of the force field from the explosion of a truncated conical reverse charge provides a pulsed load on the rock mass in the region of the end face of the borehole charge, followed by a wedging action at the level of the bottom of the ledge, which will partially or completely solve the over-drilling problem in certain rock conditions. Known methods of controlling the force field at the end of the borehole charge in order to reduce the depth of the borehole are to place a proppant in the bottom of the well to reorient the flow of explosion products to create a horizontal tear crack, to form a cumulative recess in the lower end of the charge to enhance its axial action, leaving an air gap between the end face of the charge and the bottom of the well, rounding the end surface of the bottom of the well [2-4]. The listed methods solve only one specific problem - the problem of overkill. At the same time, the use of a conical thriller in the lower part of the borehole charge is aimed at providing a set of useful phenomena that can consecutively and simultaneously deal with overbearing, provide an optimal detonation process within the borehole charge and at the same time control deformation phenomena in the surface layers of the destructible rock mass block to prevent the formation of oversized fractions. 


\section{Conclusion}

As a result of the theoretical studies, a number of new data on the mechanism of the development of the force field around the conical charge and the relationship of its shape and intensity with the conditions of application of the initiating pulse were obtained. Determined that:

- the contour of the family of isolines of the density of detonation products around a truncated conical charge does not depend on the initiation conditions in nature and is associated only with the form of the charge, namely, the presence of characteristic surfaces in the transverse conical section, along the normal to which the particles of DD particles expand;

- the development of the initiation process from one of the two bases of the truncated cone determines the predominant propagation of the energy flow towards the opposite base of the cone and beyond, and regardless of the place of initiation on a smaller cone base, a leading impulse is observed, which further stops development, merging with the side wings "Force field;

- the "pear-shaped" nature of the structure of the force field from the explosion of a conical charge creates opportunities for using the phenomenon to solve the problem of overbending, especially in brittle rocks and rocks of medium strength;

- the simultaneous lower initiation of the system of adjacent borehole charges by conicalshaped fighters ensures the interaction of counter propagating stress waves and mass displacements of the rock mass in the vertical plane, orientes the total displacement vector in the wedge-shaped mode by cutting to the side of the surface rock layer at the packing level and enhances the destructive effect of a mass explosion in it sense of reducing the output of oversized fractions.

\section{REFERENCES}

1. В.А.Одинцов, Ю.М.Сидоренко, \& В.С.Туберозов. (2000) «Моделирование процесса взрыва осколочно-фугасного снаряда с помощью двумерного кода.» Исследования, конструирование, испытания. №1-2. - С. 49-55.

2. Pejev A. (2004) «Influence of the shape of the charge in the bottom of the hole on the degree of processing of the sole of the ledge.» Transactions of Kremenchuk Mykhailo Ostrogradsky State Politechnic University,. vol.1, no. 24.- pp.63-64.

3. М. В. Помазан, \& О. А. Юрко. (2017) «Про зниження перебуру при використанні свердловинного заряду з кумулятивним ефектом.» Сучасні ресурсоенергозберігаючі технології гірничого виробниџтва - Науково-виробничий журнал: Кременчуцький національний університет імені Михайла Остроградського. Кременчук: КрНУ,. Випуск 2(20). -C. 61-70.

4. В.В.Воробьев, М.В.Помазан, С.В.Шлык, \& Л.Д.Воробьева (2017) «Моделирование динамического разрушения донной части скважины с учетом концентратора напряжений.» Восточно-европейский журнал передовых технологий. 3/1(87). 